\title{
EFFECT OF THE DEMOGRAPHIC PROCESSES ON THE CONDITION OF THE SETTLEMENT NETWORK IN BULGARIA
}

\author{
DOI: http://dx.doi.org/10.18509/GBP.2020.41 \\ UDC: 314.116:711.45(497.2)"1905/2017"
}

\section{Toni Traykov}

Sofia University "St. Kliment Ohridski, Bulgaria

\begin{abstract}
The emergence and development of the settlements and settlement network is determined by the operation of various factors and conditions. In addition to the determining role of the socio-economic factors, of importance are also the changes related to the peculiarities and trends in the demographic processes. The periods of peaceful development and economic stabilization usually lead to population growth and positive changes in the urban network. In the case of Bulgaria, this correlation has manifested itself in its new and recent history, since the Liberation (1878) to the beginning of the 21 st century. The processes of economic stabilization during the peacetime periods in the last century were accompanied by positive development of the existing settlement network in the country. An exception is the adverse change resulting from the demographic crisis that occurred in the second half of the 20th century. As a result of the serious demographic situation and the issuing depopulation process, there occurred significant changes in the number and size of settlements. The decreasing population of the country has affected most seriously the rural areas and has resulted in a growing number of villages with a minimum population. The negative trends in the demographic development have also affected the development of the towns. Despite the significant increase in the number of towns since World War II, the towns also saw a population decrease that began at the end of the last century. A typical example in this regard is the decreasing number of larger towns in the country with a population of over 100 thousand inhabitants.
\end{abstract}

Keywords: population of Bulgaria, demographic processes, settlement network

\section{INTRODUCTION}

The formation of the modern settlement network in Bulgaria is the result of the continuous development of the settlements over the different historical periods. Bulgaria is one of the transition countries in Eastern Europe, which has a strong demographic decline. The factors that determine the great unevenness in the development of its population are the territorial changes in the first half of the last century, the internal and external migration of the population and its natural movement [1]. Various factors influence this development: socio-economic, natural, geopolitical, etc. Last but not least, the demographic factor is related to the population density of the territory, the total number and the structural characteristics of the population. Geographic features in the natural and mechanical movement of the population have a certain influence on the changes in the size and territorial distribution of the settlements in our country. Most often their influence is combined with changes in the socio-political conditions and the extent of the territory of the country during the different stages of its historical development. Reliable data documenting the extent of this influence exist with the introduction of regular demographic statistics in Bulgaria after its Liberation from Ottoman rule (1878). The first 
organized census of the population in the Principality of Bulgaria was in 1881, and in the existing for a short period of time the autonomous region of Eastern Rumelia - in 1884. The first census after the Unification of the Principality of Bulgaria and Eastern Rumelia (1885) was carried out in 1887. From then until 2011. in Bulgaria a total of 17 censuses were conducted. The statistics on the natural movement of the population in Bulgaria were established as early as the beginning of 1881, shortly after the completion of the first census of the population in the Principality of Bulgaria. Since then, Bulgarian statistics regularly collects, develops and publishes statistical data on births, marriages and deaths in separate annual editions (M. Minkov, 1997). The beginning of the current demographic statistics in Bulgaria is considered to be the adoption of a special law entitled "Regulations for noting births, marriages and deaths in the Principality of Bulgaria", issued in 1880. Initially, the registration of events on the civil status of the population was carried out by the church authorities. They undertook to keep three types of registers (births, marriages and deaths) and, at the end of each calendar year, to transmit national statistics for the production of statistical information. Since 1893 the registration of the civil status of the population in Bulgaria has been transferred to the municipal administrations [3]. The collection of census data and current demographic statistics allow tracking the changes in the urban network and the two main types of settlements cities and villages. For example, according to the first census in Bulgaria (1887), 74 cities were registered in the Principality of Bulgaria, and the share of urban population was only $18.8 \%$.

\section{DATA \& METHODS}

The normalization of the political and socio-economic conditions in Bulgaria after the Liberation (1878) created significantly better and quieter living and economic conditions. The relatively long peacetime period from the Liberation (1878) to the Balkan War (1912) related to economic stabilization and the development of the Third Bulgarian State had a favorable effect on demographic and settlement development. As a result of the positive values of natural growth, the population began to grow at a steady pace, despite the displacement of part of the country's Turks, Tatars and almost the entire Circassian population.

In his study of the demographic development of Bulgaria A. Totev (1992) defined the period 1880-1911. such as high fertility (about $40 \%$ ), high infant mortality (about 150 $\%$ ), high total mortality (about $20 \%$ ) and high natural population growth (about $20 \%$ ). With these values of natural growth, regardless of the expatriation, the country's population is growing at about $1.0-2.0 \%$ annual average. Population growth as a whole also leads to an increase in the number of inhabitants in individual settlements. The return of the Bulgarian population from the mountainous and semi-mountainous settlements of the country to the villages and cities in the lowlands and plains leads to their quantitative growth and restoration of their Bulgarian appearance. The census conducted in 1905. 5018 settlements were registered within the boundaries of the then Principality of Bulgaria, incl. 80 cities, 3838 villages and 1100 neighborhoods and huts. Almost the same distribution is maintained at the next census in 1910. (80 towns, 3839 villages and 1099 neighborhoods and huts). The agrarian orientation prevailing at that time in the economic development of the country and the low degree of urbanization in its territory was reflected both in the small number of urban settlements and in their relatively small sizes. A characteristic feature of the period before the wars of 1912-1918. is the preservation of 
a large number of scattered settlements (neighborhoods and huts) associated with extensive agriculture in the mountainous and semi-mountainous territories.

As a result of the long military period (1912-1918) negative changes occurred in the demographic and settlement development of Bulgaria. In three of the years $(1913,1917$ and 1918) there was a negative natural population growth. It is the result of the declining birth rate and high overall mortality caused by the huge number of casualties on the fronts, epidemics of communicable diseases and malnutrition during the wars. The loss of territories by virtue of the Neuilly Peace Treaty causes refugee flows of Bulgarian population from territories left outside the new state borders. New villages are being set up in different parts of the country in connection with the accommodation of refugees. At the same time, refugee neighborhoods are emerging in larger cities. The names of these neighborhoods were most often related to the places where the refugees came from (Thracian, Macedonian, Dobrudzha, etc.). The loss of the Western Suburbs and South Dobrudzha leads to a decrease in the number of settlements. Thus, by virtue of the 1919 peace treaty. Bulgaria is losing the cities of Dobrich, Silistra, Tutrakan, Balchik, Kavarna, Caribrod, Bosilegrad and Strumitsa [5].

The next peacetime period between the two world wars (1919-1939) for Bulgaria was characterized by the passage of postwar demographic compensation (1920-1924) and the subsequent gradual decline in the values of fertility, mortality and natural growth. For the period 1921-1945. the birth rate decreases from about $40 \%$ to about $22 \%$, the mortality rate from about $20 \%$ to about $14 \%$, and the natural increase from about $20 \%$ to about $8 \%$. As a result of population growth naturally and the influx of refugees from other Bulgarian ethnic territories abroad, the number of settlements in Bulgaria is increasing. On the eve of World War II (1939), 5761 settlements existed in the Kingdom of Bulgaria, of which 94 cities, 4,285 villages and 1,371 neighborhoods and huts. By virtue of the Craiova Agreement (1940), Bulgaria reclaimed the territory of South Dobrudzha and this led to an increase in the number of settlements, including cities. Under the agreement, Dobrich, Silistra, Tutrakan, Balchik and Kavarna were re-annexed to the Kingdom. The slow progress of the urbanization processes in Bulgaria until the Second World War is the reason for the slow increase in the number of cities and their population. At that time, some villages were larger in population than their surrounding centers. For example, the villages of Kneja and Kozloduy existing at that time were more populous than their surrounding center - the town of Oryahovo. At the 1946 census. in Bulgaria the cities are increasing to 104 , and the urban population is $24.3 \%$. Among the cities, then, the small size of the population prevailed. At the same time, until the Second World War, a large number of scattered settlements (neighborhoods and huts) remained in our country [4]. The radical political and socio-economic changes in Bulgaria after 1944 lead to disruption of the natural course of its demographic and urban development. Compulsory and widespread co-operation in agriculture and the creation of industrial enterprises, which are inconsistent with the scale and traditions of the country, cause mass migration of the population from villages to cities. Deprived farmers who receive low remuneration in the established CAs are forced to target cities. The displacement of a young able-bodied population has led to a rapid decline in the rural population since 1946, and in the coming decades to its intense aging. Low birth rates and urban migration create conditions for negative changes in rural settlements in different parts of the country. At the same time as their number decreases, their average size decreases as the number of inhabitants. In the aftermath of the Second World War, a number of small villages, neighborhoods, and huts became depopulated and dropped from the list of settlements. Left without a working 
age population, much of the rural settlements were still doomed to dying out. During the period 1939-1987. the total number of settlements in Bulgaria decreased from 5761 to 4994. During the same period the decrease in the neighborhoods and huts was greatest from 1371 to 348 [7]. The decrease in the villages - from 4285 to 4114 was much smaller. At the same time it increased sharply. the number of cities - from 94 in 1939. at 237 in 1987. The rapid increase in the share of the urban population and the number of cities in Bulgaria was regarded as a prestigious achievement of the socialist government of the state. In practice, changes related to the mechanical growth of cities have accelerated the intense depopulation in rural areas in the country. The areas of the mountain, semimountain and border areas (Stara Planina, Predbalkana, Strandzha - Sakar, Sredna Gora and Kraishte) are particularly affected. At the same time, the announcement of new urban settlements was mainly based on the achievement of quantitative indicators, without taking into account the qualitative aspects related to the requirements for urban development and urban life. The announcement of some of the new cities (Pravets, Loznitsa, etc.) was in line with the desire to be prominent in the development of the native villages of prominent party figures from the time of socialism.

The rapid growth of urban residents, which began in the 1950s, has led to serious demographic, economic and social problems in their development. Among them, according to Z. Ninov (1997), the deepening housing crisis, the backlog in the construction of technical and social infrastructure (health establishments, schools, cultural and everyday objects, etc.) had a major place. Creation of large metallurgical, chemical and others plants, without the necessary treatment facilities, caused significant environmental pollution around the cities - the industrial centers (Sofia, Pernik, Dimitrovgrad, Pirdop, Zlatitsa, etc.). The transboundary air pollution in some Danube cities such as Rousse and Silistra has also contributed to the deterioration of the ecological environment and the subsequent outflow of population.

The problems inherited from the period of socialism in the socio-economic and demographic development of Bulgaria predetermined the negative changes in the settlement network during the transition period to a market economy, which began after 1989. Deteriorated living conditions as a result of the economic crisis in the 1990s have been reflected in the reproductive and migration attitudes and behavior of the population [6].

Against the background of the general unfavorable trends related to the demographic crisis in Bulgaria, the changes in the number and structure of the population in the villages are defined as catastrophic and irreversible [2]. Despite the known rise in fertility rates at the beginning of this century, the demographic situation in both urban and rural populations remains a major negative factor for the development of settlements and the urban network in the early 21 st century. The data unequivocally show a continued decrease in residents in cities and villages, leading to an increase in the number of small towns and villages and the deletion of settlements left without a permanent population. During the period 1992-2017. the villages in Bulgaria decrease from 5098 to 4999, and the number of villages includes the existing up to 1995 neighborhoods, huts, train stations and more. settlements. During the same period the number of villages with population less than 200 inhabitants increased from 1981 to 2599. From 1992 to 2017. the number of cities in Bulgaria increased from 238 to 257 . The demographic crisis also affected their development. The slower decline in the urban population, compared to the rural one, has led to a steady increase in its relative share. During that period, the number of cities with a population of less than 5,000 inhabitants increased from 74 to 98 . Negative changes 
were also observed in the largest urban settlements. For example, cities with a population of over 100,000 have declined from 9 in 1992. at 6 in 2017 Among them stands out Sofia, with a population of over 1 million inhabitants. The negative trends in urban development are indicated by the fact that between the two censuses in 2001 and 2011. only 4 of the regional centers have positive population growth - Sofia, Varna, Burgas and Veliko Tarnovo.

According to the National Statistical Institute, as of December 31, 20185159129 people live in the cities, or $73.7 \%$, and 1840910 people in the villages, or $26.3 \%$ of the country's population. By the end of the same year the settlements in Bulgaria were 5256, of which 257 were cities and 4999 were villages. The populated settlements are 164 with the highest number in the mountainous and semi-mountainous parts of the districts of Gabrovo (64), Veliko Turnovo (55) and Kardzhali (11). At the same time, the trend of concentration of population in a small number of settlements continues. For example, in six cities with a population of over 100,000 inhabitants $34.4 \%$ of the country's population live.

\section{DISSCUSION \& CONCLUSION}

In the near future, the optimization of the existing settlement network in the country requires taking into account the real demographic situation and its regional peculiarities. Measures for the development of different populated areas should include a comprehensive analysis of all the factors and conditions affecting urban development. The socio-economic changes that determine the standard of living of the population and its reproductive and migratory attitudes and behavior should be of major importance for it. The future development of the urban network requires a comprehensive concept, the main place in which to build urban centers supporting more balanced territorial development and reducing the disparities between central urban and peripheral rural areas.

\section{REFERENCES}

[1] Naydenov Kl. Modern migration processes and attitudes of the population in the Republic of Bulgaria - factors and trends, International Scientific Conference GEOBALCANICA 2019, http://dx.doi.org/10.18509/GBP.2019.50

[2] Naydenov Kl. Human resources development as a factor for regional development, International Multidisciplinary Scientific GeoConference: SGEM, 2019, doi: $10.5593 /$ sgem2019/5.4/S23.063

[3] Kovachev, N. Changes in the administrative-urban division, in the naming and renaming of settlements in the country. Settlement Research Archive, year 4, vol. 3-4, Edition of VTU, Veliko Turnovo, 1995.

[4] Minkov, M. Demography, S., 1999.

[5] Ninov, Z. Emergence and development of settlements and the urban network. Geography of Bulgaria. Physical and socio-economic geography. Ed. BAS, S., 1997.

[6] Totev, A. A brief outline of the demographic development of Bulgaria. Cc. Population, Ed. BAS, S., Issue 5, 1992.

[7] Traikov, T. Quantitative Dimensions of the Demographic Crisis in the Rural Population in Bulgaria. Year Sofia University "St. Kliment Ohridski ”, book. 2 - Geography, Vol. 107. 